\section{Small wonders in Africa}

\section{Paris}

DESPITE a year of government investigations into his controversial AIDS vaccine studies in Africa, French researcher Daniel Zagury is planning yet another expedition to that continent. But his principal equipment this time will more probably be a ruler than a syringe. With Arsène Burny of the University of Brussels, Zagury intends to explore a mysterious correlation between short stature and resistance to AIDS. The correlation was discovered two years ago by Belgian scientist Philippe Van de Per and his colleagues in Rwanda in a group of about 700 children infected at birth by their HIV-positive mothers.

Most seropositive babies die in their second or third year. But 14 of these Rwandan children have shown a remarkable ability to survive; all are more than four years old, and some have reached the age of 14 with relatively good health. If Zagury's hypothesis is correct, these children can thank an excess of the neuropep-

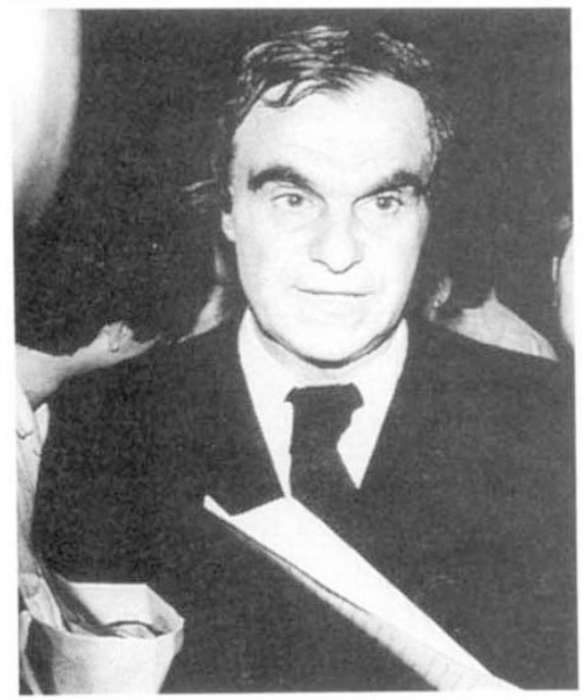

Zagury finds advantages in shortness

tide somostatin for their longevity. Just as somostatin inhibits the growth hormone somatropin in the endocrine system, Zagury believes it may suppress the damaging effect of the human immunodeficiency virus (HIV) on the immune system. That, he argues, may have delayed the onset of AIDS in the children.

Contrary to rumours circulating in $\mathrm{Pa}$ risian laboratories about the discovery, Zagury says, the AIDS-free children "are not pygmies, they're just very short." He says that although he had suspected a link between the growth regulatory system and the immune system, it was not until he and Burny actually explored the health records of the small group of healthy children that they found some confirmation. "We immediately saw that they share a common clinical denominator - their size. They are not dwarfs, but they're just above CLINICAL TRAILS that." Testing the blood of the children confirmed unusually high levels of somostatin and, as a result, low levels of growth hormone.

Robert Gallo, a US AIDS researchers at the National Institutes of Health, has seen Zagury's data and says the implications are "very interesting". But he is reluctant to draw conclusions until Zagury and Burny get more samples from a larger group of seropositive children, something the researchers plan to do next year. "There is definitely a correlation with stature [and delayed onset of AIDS] in their data," Gallo says, "but I don't know how far to push it yet." Nevertheless, he describes the discovery as "a startling lead".

The children are not entirely healthy; their CD4 cell count is only in the range of 200 to 400 - about one-third of normal levels. But that is still well over the cell count that a person with full-blown AIDS might have. And the children are still alive, something that Zagury finds most persuasive of all. If somostatin can indeed suppress the effects of HIV, he argues, science could have a powerful tool in the struggle to keep AIDS patients alive.

Christopher Anderson

\title{
Blazing an ethical trail
}

\section{Washington}

A CLINICAL trial to examine whether the AIDS drug zidovudine (AZT) can reduce the transmission of human immunodeficiency virus (HIV) from pregnant women to their fetuses is now getting under way, having tiptoed its way through an ethical mine field on the way to approval. As one of the few major trials of a drug known to have toxic side-effects to focus on pregnant women, the new study has broken new ethical ground, and may have cleared an easier path for subsequent studies looking for ways to prevent the transmission of HIV from infected mother to fetus.

The trial is still opposed by a number of AIDS advocacy groups, who argue that the study neglects the health needs of the HIV-infected women themselves, but such criticism from activists is not uncommon. What is uncommon is the intensity of the ethical debate that the trial triggered among medical researchers, pitting paediatricians against AIDS researchers.

The proposed study was predicated on the assumption that if the number of viral particles circulating in the mothers' blood can be reduced, then transmission of HIV to their fetuses (reckoned to occur in up to 40 per cent of pregnancies when the mother carries the virus) will be less likely. This may be a reasonable assumption, but there is no animal model in which to test it.

Deborah Cotton, from the Harvard School of Public Health and a member of the Food and Drug Administration (FDA) Antiviral Advisory Committee that reviewed the study, says she was initially "aghast" when she learned of the plan to launch a trial giving AZT to pregnant women. AZT can have toxic side-effects, including anaemia, severe nausea and muscle wasting, which force many AIDS patients to discontinue the drug.

Catherine Wilfert, a Duke University paediatrician specializing in AIDS who was called in by the FDA to provide expert advice on the trial, says the main difficulty was reconciling the different ethical per- spectives of paediatricians and mainstream AIDS researchers. The controversy centred on the dangers of exposing fetuses to a highly toxic drug, particularly for the majority of babies born to HIV-infected women that would not, in any case, become infected. Somewhat surprisingly, the loudest protests came from AIDS researchers working with adults. This was in large part due to the tendency for these researchers to view AZT as a treatment for HIV infection, and one that should not be applied when not strictly necessary, because of its toxic effects. Wilfert says the change of heart came once the mainstream AIDS researchers became convinced that the trial should be seen as one looking at the prevention of HIV infection, rather than its treatment.

After more than two years of soulsearching and stringent review (the FDA antiviral committee is usually not asked to examine drug trials while they are still being planned), the trial was eventually approved - and with the protocol rewritten to give AZT during both the second and third trimesters of pregnancy, rather then just the third as in the original draft.

Having cleared its ethical hurdles, however, the trial now faces new obstacles. Recruitment has so far been slow - the National Institute of Allergy and Infectious Diseases (NIAID), which is coordinating the trial, hopes to include some 750 women, but since recruitment began in April, only 36 have enrolled. The main problem seems to be that HIV-infected pregnant women, many of whom are drug users, typically come from a section of society in which participation in basic health care programmes, let alone in clinical trials, is poor. "These women are about as disadvantaged as they come," Cotton observes. Given this constraint, James Balsley, medical officer for the study at NIAID, says it could take three years to enrol the full complement of 700 -plus women. 